\title{
PENGARUH BUDAYA ORGANISASI TERHADAP KEPUASAN KERJA DOSEN TETAP UNIVERSITAS BUNDA MULIA \\ Oktafalia Marisa
}

Email: omuzammil@bundamulia.ac.id

\section{Penulis}

Oktafalia, adalah pengajar tetap di Universitas Bunda Mulia dengan bidang peminatan pada rumpun kuantitatif dan mata kuliah perbankan

\section{Abstract}

Each person have a very unique characteristic, it makes every organization or companies should bring those differences into a right lane. One of the tool to lead the diferrences is organization culture. This research tries to find out the effect of organizational culture to works satisfaction. The sample of this research are the full timer lecturers works in Bunda Mulia University. The result of this research shown us that there is a posifif and significant effect of organizational culture to works satisfaction. The result of the research will provide a basic information about organizational culture in Bunda Mulia, what lecturer feel about that and how that's change affected their performances. Hopefully this research could provided a comprehensif data to develop any research in the future

\section{Key Words}

Organization culture, lecturers, work satisfaction 


\section{PENDAHULUAN}

Perkembangan ilmu pengetahuan dan teknologi yang pesat akan menimbulkan berbagai perubahan dalam berbagai aspek kehidupan. Termasuk didalamnya perubahan dalam dunia pendidikan yang semakin menuntut iklim yang kompetitif. Setiap universitas saat ini selalu menginkan menjadi yang lebih unggul daripada perguruan tinggi pesaingnya. Persaingan yang ketat tersebut tentunya menuntut tiap perguruan tinggi untuk memiliki asset yang handal sebagai amunisi bersaing, salah satu asset yang wajib dimiliki ialah kesiapan sumberdaya tenaga pengajar sebagai bagian dari core akademik setiap perguruan tinggi

Tenaga pengajar atau dosen adalah seorang yang berdasarkan pendidikan dan keahliannya diangkat oleh penyelenggara perguruan tinggi dengan tugas utama mengajar diperguruan tinggi dengan tugas pokok, wewenang dan tanggung jawab di bidang pendidikan dan pengajaran,penelitian dan pengabdian pada masyarakat. Tenaga pengajar atau Dosen mungkin bukanlah satu satunya faktor penentu sukses nya suatu perguruan tinggi, namun kinerja mereka adalah salah satu aspek penting dalam penyelenggaraan kegiatan pendidikan.

Beberapa penelitian menyatakan kinerja dari sumber daya manusia dipengaruhi oleh kepuasan kerja dari sumber daya manusia tersebut, sedangkan kepuasan kerja sendiri dipengaruhi oleh budaya organisasi yang ada di setiap organisasi tempat mereka berasa. Budaya organisasi merupakan suatu sistem makna yang dianut oleh anggota-anggota di suatu organisasi yang membedakan antara organisasi yang satu dengan yang lain. Budaya organisasi dapat menjadi suatu instrument keunggulan kompetitif yang utama, yaitu bila budaya organisasi dapat menjawab atau mengatasi tantangan lingkungan dengan tepat dan cepat.

Budaya organisasi yang tepat dipercaya memberikan pengaruh yang baik dalam menghasilkan Sumber Daya Manusia yang berkualitas untuk melaksanakan tugas secara efektif dan efisien. Namun apabila budaya organisasi yang diterapkan tidak sesuai maka akan dapat menghambat kinerja karyawan sehingga pencapaian tujuan dan sasaran perusahaan sehingga kinerja perusahaan akan terhambat. 
Sasaran dan tujuan perusahaan atau dalam penelitian ini adalah universitas Bunda Mulia juga tidak terlepas dari budaya organisasi yang tepat dan sesuai dengan keinginan serta kebutuhan dosen tetap sebagai salah satu bagian dari kesatuan karyawan sehingga dapat mendorong kepuasan kerja, yang pada akhirnya akan mendorong karyawan bekerja lebih giat dan lebih baik, menumbuhkan kenyamanan dan loyalitas karyawan terhadap perusahaan yang pada akhirnya diharapkan dapat menunjang pencapaian tujuan dan sasaran dari Universitas Bunda Mulia tersebut.

\section{Kepuasan Kerja}

Berdasarkan survei yang dilakukan (Herzberg 1959), ia berkesimpulan bahwa pendekatan-pendekatan yang dilakukan oleh para peneliti untuk memecahkan masalah kepuasan kerja tidaklah lengkap. Untuk membuktikan pendapatnya itu, Herzberg dan sejawatnya pada tahun 1959 melakukan penelitian terhadap 200 orang insinyur dan akuntan Pittsburg. Kepada mereka diminta untuk mengambarkan secara detail bilamana mereka merasa puasa dan tidak puas dengan pekerjaannya.

Dari analisa yang dilakukan terhadap data yang terkumpul, Herzberg dan sejawatnya menyimpulkan bahwa faktor-faktor yang menimbulkan kepuasan kerja adalah

\section{Motivator Factor}

Motivator factor berhubungan dengan aspek-aspek yang terkandung dalam pekerjaan itu sendiri. Jadi berhubungan dengan job content atau disebut juga sebagai aspek intrinsik dalam pekerjaan. Faktor-faktor yang termasuk di sini adalah:

1) Achievement (keberhasilan menyelesaikan tugas)

2) Recognition (penghargaan)

3) Work it self (pekerjaan itu sendiri)

4)Responsibility(tanggungjawab) 


\section{b. Hygiene factor}

Hygiene factor ini adalah faktor yang berada di sekitar pelaksanaan pekerjaan; berhubungan dengan job context atau aspek ekstrinsik pekerja. faktor-faktor yang termasuk di sini adalah:

1) Working condition (kondisi kerja)

2) Interpersonal relation (hubungan antar pribadi)

3)Company policy and administration (kebijaksanaan perusahaan dan pelaksanaannya)

4) Supervision technical (teknik pengawasan)

5) Job security (perasaan aman dalam bekerja)

Menurut (Herzberg 1959), perbaikan terhadap faktor-faktor ini akan mengurangi atau menghilangkan ketidakpuasan, tetapi tidak akan menimbulkan kepuasan kerja karena ini bukan sumber kepuasan kerja. Prinsip dasar dari dinamika faktor ini adalah sebagai berikut:

1) Hygiene factor dapat mencegah atau membatasi ketidakpuasan kerja, tetapi tidak dapat memperbaiki kepuasan kerja.

2) Perbaikan dalam motivator factor dapat mencegah kepuasan kerja, tetapi tidak dapat mencapai ketidakpuasan kerja.

Menurut (Wexley and Yukl 1977), kepuasan kerja ditentukan atau dipengaruhi oleh sekelompok faktor. Faktor-faktor itu dapat dikelompokan ke dalam tiga bagian, yaitu yang termasuk dalam karakteristik individu, variabel situasional, karakteristik pekerjaan.

1) Karakter individu, yang meliputi: kebutuhan-kebutuhan individu, nilai-nilai yang dianut individu (values), dan ciri-ciri kepribadian (personality traits).

2) Variabel-variabel yang bersifat situasional, yang meliputi: perbandingan terhadap situasi sosial yang ada, kelompok acuan, pengaruh dari pengalaman kerja sebelumnya. 
3) Karakteristik pekerjaan, yang meliputi: imbalan yang diterima, pengawasan yang dilakukan oleh atasan, pekerjaan itu sendiri, hubungan antara rekan sekerja, keamanan kerja, kesempatan untuk memperoleh perubahan status.

\section{Faktor yang meningkatkan kepuasan kerja}

Menurut (Robbins 2006) terdapat lima faktor penting dalam meningkatkan kepuasan kerja, yaitu:

1. Kerja yang menantang

2. Penghargaan yang pantas

3. Kondisi kerja yang mendukung

4. Rekan kerja yang saling mendukung

5. Kesesuaian pribadi dengan pekerjaan

\section{Efek Kepuasan Kerja pada Kinerja}

Ada beberapa efek kepuasan kerja pada kinerja (Robbins 2006), yaitu:

1. Kepuasan kerja memberi efek pada produktivitas, kalau tidak puas cenderung produktivitas menurun

2. Kepuasan kerja memberi efek pada absensi, kalau tidak puas akan tinggi tingkat kemangkiran (absensi)

3. Kepuasan kerja memberi efek pada keluarnya karyawan (Labor Turn Over) kalau tidak puas LTO akan tinggi

\section{Perumusan Masalah}

Mengingat adanya keterbatasan didalam melaksanakan penelitian, maka sebelum melakukan perumusan masalah akan dilakukan pembatasan masalah terlebih dahulu. Ada pun pembatasan masalah yang di kemukakan adalah sebagai berikut:

a. Budaya organisasi yang diteliti adalah budaya organisasi yang diterapkan oleh Universitas Bunda Mulia (UBM)

b. Sampel yang diambil adalah seluruh Dosen Tetap pada Universitas Bunda Mulia (UBM) di Jakarta pada periode semester genap 2008/2009 
c. Dimensi kepuasan kerja yang diteliti adalah kerja yang menantang, penghargaan yang pantas. Kondisi kerja yang mendukung dan kesesuaian pribadi dengan pekerjaan

Berdasarkan pembatasan masalah yang telah dikemukakan diatas, maka perumusan masalah dalam skripsi ini adalah "Apakah terdapat pengaruh yang signifikan budaya organisasi terhadap kepuasan kerja Dosen Tetap Universitas Bunda Mulia di Jakarta?”

\section{Tujuan Penelitian}

Adapun tujuan penelitian ini adalah untuk mengetahui bagaimanakah budaya organisasi yang diterapkan oleh Universitas Bunda Mulia berpengaruh pada kepuasan kerja dosen tetap Universitas Bunda Mulia.

\section{KERANGKA PEMIKIRAN}

Penelitian ini bertujuan untuk melihat bagaimanakah pengaruh dari budaya organisasi yang ada pada Universitas Bunda Mulia terhadap kepuasan kerja para dosen tetap, bilamana budaya organisasi yang di terapkan sesuai maka kepuasan kerja akan tercapai sehingga kinerja para karyawan dalam hal ini dosen tetap akan baik yang tentunya akan mendukung pencapaian tujuan dari universitas Bunda Mulia

\section{Hipotesis Penelitian}

Dalam penelitian ini di bentuk hipotesis sebagai berikut

$\mathrm{H} 1$ = Terdapat pengaruh positif yang signifikan dari budaya organisasi terhadap kepuasan kerja dosen tetap pada Universitas Bunda Mulia di Jakarta 


\section{METODOLOGI PENELITIAN}

\section{Populasi dan Metode Pemilihan Sampel}

(Sugiyono 2005) Populasi adalah wilayah generalisasi yang terdiri atas obyek/subyek yang mempunyai kualitas dan karakteristik tertentu yang ditetapkan oleh peneliti untuk dipelajari dan kemudian ditarik kesimpulan.

Dalam penelitian ini yang menjadi populasi adalah seluruh dosen pada universitas Bunda Mulia.

Metode pemilihan sampel dalam penelitian ini adalah pengambilan sample non probability sampling dimana semua elemen populasi tidak memiliki kesempatan yang sama untuk dipilih menjadi anggota sampel. (Husein, 2005:90), karena penelitian ini membatasi sampel hanya untuk dosen tetap yang menjadi karyawan tetap pada Universitas Bunda Mulia saja.

\section{Metode Pengumpulan Data}

Metode pengumpulan data dalam penelitian ini adalah dengan kuesioner (angket). Kuesioner dalam penelitian ini adalah suatu daftar pertanyaan yang akan ditanyakan kepada responden (sample penelitian).

kuesioner dalam penelitian ini terdiri dari kuesioner perubahan manajemen UBM dan kuesioner kepuasan kerja yang disusun oleh penulis dengan menggunakan informasi dari beberapa buku Sumber Daya Manusia dan pihak-pihak yang terkait dengan topik penelitian ini.

\section{Teknik Analisa Data}

\section{Statistik Deskriptif}

Statistik deskriptif adalah metode statistik yang digunakan untuk pengumpulan data, peringkasan, penyajian data sehingga memberikan informasi yang dibutuhkan. Dalam penelitian ini seperti yang sudah diuraikan diatas akan merangkum hasil dari kuesioner yang disebarkan oleh seluruh anggota penelitian. 


\section{Skala Pengukuran Kuesioner}

Skala pengukuran yang digunakan di dalam kuesioner adalah skala Likert. Skala Likert yang digunakan terdiri dari 5 point, yaitu dari skala 1 (sangat tidak setuju) sampai dengan skala 5 (sangat setuju)

\section{ANALISIS DAN PEMBAHASAN}

\section{Uji Validitas dan Reliabilitas}

Uji validitas dilakukan dengan menggunakan program SPSS for Windows. Untuk mengetahui apakah tiap butir pernyataan valid atau tidak maka dilakukan perbandingan Corrected Item-Total Correlation dengan tabel $\mathrm{r} \mathrm{r}_{0,05 / 2(33-2)}=0,355$. Jika corrected item-total correlation > rtabel maka dapat dikatakan butir pernyataan tersebut valid. Uji reliabilitas juga dilakukan dengan menggunakan program SPSS for Windows. Apabila nilai coefficient alpha 0,6 atau kurang maka dapat dikatakan tidak reliabel.

Uji validitas dan reliabilitas dilakukan secara bertahap. Uji validitas dilakukan terlebih dahulu baru setelah itu dilakukan uji reliabilitas.

Uji validitas pertama kali dilakukan pada variabel Kepuasan terlebih dahulu dan dari data yang diolah, diperoleh hasil output sebagai berikut 
Tabel 1

Uji Validitas pada Variabel Budaya Organisasi

\begin{tabular}{|l|c|}
\hline \multicolumn{1}{|c|}{ Pertanyaan } & $\begin{array}{c}\text { Corrected } \\
\text { Item-Total } \\
\text { Correlation }\end{array}$ \\
\hline $\begin{array}{l}\text { 1. Perusahaan (UBM) memberikan tanggung jawab yang besar } \\
\text { kepada dosen dalam bekerja. }\end{array}$ & 0.499 \\
\hline $\begin{array}{l}\text { 2. Perusahaan(UBM)memberikan keleluasaan terhadap kreativitas } \\
\text { dan kemandirian setiap dosen. }\end{array}$ & 0.520 \\
\hline $\begin{array}{l}\text { 3. Atasan memberikan karyawan kebebasan dalam } \\
\text { menyelesaikan pekerjaan. }\end{array}$ & 0.360 \\
\hline 4. Perusahaan (UBM) menjelaskan tugas perusahaan secara terperinci & 0.390 \\
\hline $\begin{array}{l}\text { 5. Suasana dan kondisi kerja yang aman dan nyaman sehingga } \\
\text { dapat bekerja dengan penuh konsentrasi. }\end{array}$ & 0.440 \\
\hline $\begin{array}{l}\text { 6. Atasan secara rutin sering mengadakan rapat untuk } \\
\text { membahas perkembangan dosen. }\end{array}$ & 0.375 \\
\hline $\begin{array}{l}\text { 7. Perusahaan (UBM) memberikan penghargaan bagi dosen } \\
\text { yang berprestasi. }\end{array}$ & 0,444 \\
\hline $\begin{array}{l}\text { 8. Perusahaan (UBM) menuntut dosen untuk mematuhi standar } \\
\text { kerja yang telah ditentukan. }\end{array}$ & 0,695 \\
\hline 9. Atasan menekankan penyelesaian pekerjaan tepat waktu & 0,495 \\
\hline $\begin{array}{l}\text { 10. Perusahaan (UBM) memberikan kesempatan untuk mengembangkan karir } \\
\text { melalui promosi }\end{array}$ & 0,655 \\
\hline 11. Atasan mengikutsertakan dosen dalam pengambilan keputusan. & 0.385 \\
\hline $\begin{array}{l}\text { 12. Dosen mendapatkan imbalan yang setimpal atas } \\
\text { hasil kerja mereka. }\end{array}$ & 0.415 \\
\hline $\begin{array}{l}\text { 13. Antara dosen saling bekerjasama dan memikul tanggung } \\
\text { jawab bersama }\end{array}$ & 0.374 \\
\hline 14. Perusahaan (UBM) membuat penugasan-penugasan anggota tim & 0.365 \\
\hline 15. Dosen merasa bagian dari tim kerja perusahaan (UBM). & 0.420 \\
\hline $\begin{array}{l}\text { 16. Perusahaan (UBM) memberikan tantangan tugas untuk } \\
\text { merangsang persaingan. }\end{array}$ & 0.520 \\
\hline 17. Persaingan antar dosen merupakan hal yang biasa terjadi. \\
\hline 18. Sesama dosen saling bersaing untuk menjadi yang terbaik. \\
\hline $\begin{array}{l}\text { 19. Evaluasi kinerja dan penghargaan lebih ditekankan } \\
\text { pada senioritas }\end{array}$ & 0.3610 \\
\hline 20. Perusahaan (UBM) memiliki sistem dan tata tertib dosen yang jelas. \\
\hline $\begin{array}{l}\text { 21. Perusahaan (UBM) mempunyai metode penyelesaian tugas yang harus } \\
\text { dilakukan dosen }\end{array}$ & 0.380 \\
\hline Sal & \\
\hline
\end{tabular}

Sumber : diolah penulis 
Berdasarkan Tabel 1 maka dapat dilihat bahwa seluruh butir pernyataan valid karena mempunyai nilai corrected item-total correlation yang lebih besar dari nilai rtabel yaitu sebesar 0,355 .

Tabel 2

Uji Validitas pada Variabel Kepuasan Kerja

\begin{tabular}{|c|c|}
\hline Pertanyaan & $\begin{array}{l}\text { Corrected } \\
\text { Item-Total } \\
\text { Correlation }\end{array}$ \\
\hline 1. Mampu bekerja setiap saat. & 0.377 \\
\hline 2. Memiliki kesempatan untuk bekerja seorang diri dalam pekerjaan. & 0.614 \\
\hline $\begin{array}{l}\text { 3. Memiliki kesempatan untuk melakukan berbagai hal yang berbeda dari } \\
\text { waktu ke waktu. }\end{array}$ & 0.375 \\
\hline $\begin{array}{l}\text { 4. Memiliki kesempatan untuk melakukan sesuatu sesuai dengan } \\
\text { kemampuan saya. }\end{array}$ & 0.620 \\
\hline $\begin{array}{l}\text { 5. Pekerjaan saya memberikan peluang untuk kemajuan saya di masa yang } \\
\text { akan datang. }\end{array}$ & 0.390 \\
\hline 6. Menerima pembayaran yang sesuai dengan pekerjaan yang saya lakukan. & 0.414 \\
\hline 7. Memiliki kesempatan untuk mendapatkan promosi pekerjaan & 0.377 \\
\hline 8. Adanya penghargaan dalam menyelesaikan pekerjaan dengan baik. & 0.655 \\
\hline 9. Telah mencapai prestasi kerja dari pekerjaan saya. & 0.640 \\
\hline $\begin{array}{l}\text { 10. Memiliki kesempatan untuk menjadi "orang yang berarti" dalam } \\
\text { lingkungan kerja. }\end{array}$ & 0.550 \\
\hline 11. Cara perusahaan dalam menerapkan kebijakan dan peraturan & 0.644 \\
\hline 12. Kebebasan untuk mengambil keputusan sendiri. & 0.613 \\
\hline 13. Kondisi kerja yang nyaman. & 0.566 \\
\hline 14. Atasan saya mampu menangani bawahannya. & 0.539 \\
\hline 15. Atasan saya mampu mengambil keputusan. & 0.542 \\
\hline 16. Memiliki kesempatan untuk membantu rekan kerja yang lain & 0.618 \\
\hline $\begin{array}{l}\text { 17. Memiliki kesempatan untuk memberitahukan rekan kerja } \\
\text { yang lain mengenai apa yang harus dikerjakan. }\end{array}$ & 0.532 \\
\hline 18. Sesama rekan kerja memiliki hubungan baik antara satu sama lain & 0.642 \\
\hline 19. Mampu untuk menyelesaikan berbagai hal sesuai hati nurani saya. & 0.534 \\
\hline $\begin{array}{l}\text { 20. Memiliki kesempatan untuk mencoba metode sendiridalam melaksanakan } \\
\text { pekerjaan. }\end{array}$ & 0.641 \\
\hline
\end{tabular}

Sumber : diolah penulis 
Berdasarkan Tabel 1 maka dapat dilihat bahwa seluruh butir pernyataan $\mathrm{k}$ valid karena mempunyai nilai corrected item-total correlation yang lebih besar dari nilai rtabel yaitu sebesar 0,355 .

Setelah uji validitas pada variabel Kepuasan dilakukan, berikutnya dilakukan uji reliabilitas untuk variabel Budaya Organisasi dan kepuasan kerja sehingga diperoleh hasil output sebagai berikut:

Tabel 3

Uji Reliabilitas pada Variabel Budaya Organisasi

\begin{tabular}{|c|}
\hline Cronbach's Alpha \\
\hline 0,755 \\
\hline
\end{tabular}

Sumber : diolah penulis

Berdasarkan hasil output yang diperoleh pada Tabel 3 didapat hasil bahwa data tersebut reliabel karena nilai cronbach's alpha atau coefficient alpha yang diperoleh adalah sebesar 0,755 lebih besar dari 0,6.

Tabel 4

Uji Reliabilitas pada Variabel Kepuasan Kerja

Sumber : diolah penulis

\begin{tabular}{|c|}
\hline Cronbach's Alpha \\
\hline 0,799 \\
\hline
\end{tabular}

Berdasarkan hasil output yang diperoleh pada Tabel 4 didapat hasil bahwa data tersebut reliabel karena nilai cronbach's alpha atau coefficient alpha yang diperoleh adalah sebesar 0,799 lebih besar dari 0,6.

\section{Uji Asumsi untuk Analisis Regresi}

Sebelum melakukan uji pengaruh dengan menggunakan analisis regresi, terlebih dahulu dilakukan uji asumsi. Uji asumsi dilakukan dengan memproses data 
menggunakan program SPSS for Windows dan hasil output yang didapat adalah sebagai berikut:

\section{Uji Normalitas}

\section{Gambar 1 \\ Normal P Plot}

Normal P-P Plot of Regression Standardized Residual

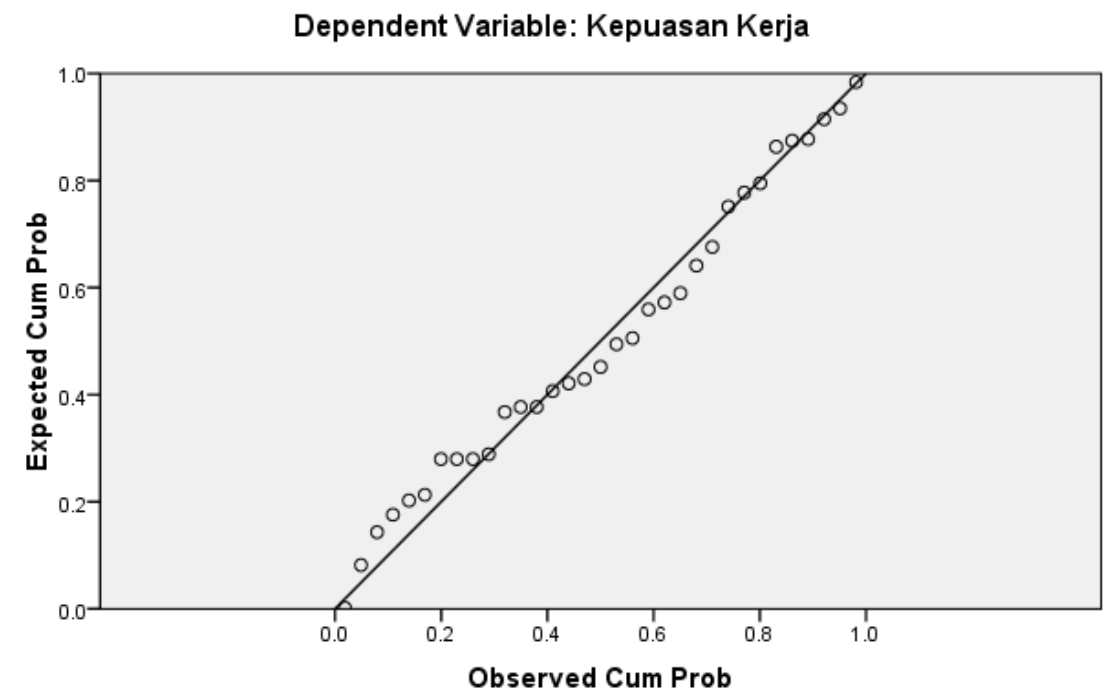

Sumber : diolah penulis

Uji asumsi pertama yang dilakukan adalah normalitas. Jika melihat pada Gambar 1, dapat dilihat bahwa data menyebar di sekitar garis diagonal dan mengikuti arah garis diagonal maka asumsi normalitas terpenuhi. 


\section{Uji Homoskedastisitas}

\section{Gambar 2}

Scatter Plot

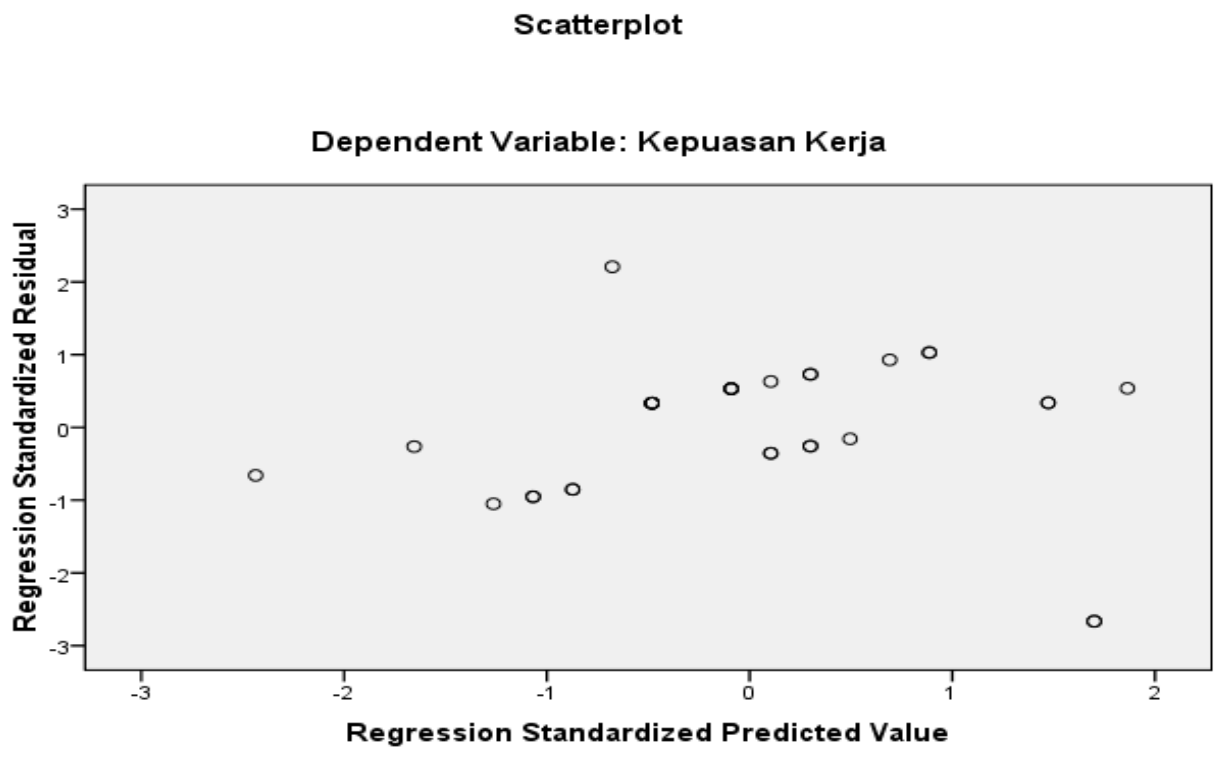

Sumber : diolah penulis

Pengujian asumsi berikutnya yang dilakukan adalah homoskedastisitas. Jika melihat pada Gambar 2, terlihat bahwa tidak ada pola yang jelas yang terbentuk pada scatter plot dan diikuti dengan penyebaran titik-titik maka asumsi homoskedastistas terpenuhi

\section{Uji Autokorelasi}

Tabel 5

Uji Autokorelasi

\begin{tabular}{|c|}
\hline Nilai D-W \\
\hline 1,825 \\
\hline
\end{tabular}

Sumber : diolah penulis 
Uji asumsi berikutnya yang dilakukan adalah autokorelasi. Merujuk pada Tabel 5, didapat nilai Durbin-Watson sebesar 1,825 maka dapat disimpulkan tidak terjadi otokorelasi.

Selanjutnya dianalisis apakah kepuasan kerja dipengaruhi oleh budaya organisasi. Berikut adalah Ouput yang diperoleh dengan menggunakan program SPSS for Windows dapat dilihat di bawah ini:

Tabel 6

Uji Pengaruh Budaya Organisasi terhadap Kepuasan Kerja

\begin{tabular}{|c|c|c|c|c|c|c|}
\hline \multicolumn{7}{|c|}{ Coefficients $^{a}$} \\
\hline \multirow{2}{*}{\multicolumn{2}{|c|}{ Model }} & \multicolumn{2}{|c|}{ Unstandardized Coefficients } & \multirow{2}{*}{$\begin{array}{c}\begin{array}{c}\text { Standardized } \\
\text { Coefficients }\end{array} \\
\text { Beta }\end{array}$} & \multirow[b]{2}{*}{$\mathrm{t}$} & \multirow[b]{2}{*}{ Sig. } \\
\hline & & $\mathrm{B}$ & Std. Error & & & \\
\hline \multirow[t]{2}{*}{1} & (Constant) & 3.309 & .830 & & 3.986 & .000 \\
\hline & Budaya Organisasi & .284 & .182 & .270 & 1.359 & .029 \\
\hline
\end{tabular}

a. Dependent Variable: Kepuasan Kerja

Sumber : diolah penulis

Jika dibandingkan nilai signifikansi $=0.029$ dengan $\alpha=5 \%$, maka dapat disimpulkan bahwa $\mathrm{H}_{0}$ ditolak artinya terdapat pengaruh positif yang signifikan Budaya Organisasi terhadap kepuasan kerja dengan tingkat keyakinan 95\%

Tabel 7

\section{Koefisien Determinasi Budaya Organisasi terhadap Kepercayaan}

\begin{tabular}{|l|l|}
\hline$R$ & R Square \\
\hline 0,8279 & 0,6854 \\
\hline
\end{tabular}

Sumber : diolah penulis

Nilai R Square menginformasikan bahwa koefisien determinasi yang didapat dari hasil pengolahan yang terlihat pada Tabel 7 sebesar 0,6854 mengindikasikan bahwa 68,54 \% dari kepuasan kerja dapat dijelaskan oleh budaya organisasi sementara sisanya dapat dijelaskan oleh faktor-faktor lainnya. 


\section{KESIMPULAN DAN SARAN}

\section{Kesimpulan}

Setelah melakukan analisis mengenai pengaruh budaya organisasi terhadap kepuasan kerja dosen tetap Universitas Bunda Mulia maka diperoleh kesimpulan bahwa terdapat pengaruh yang signifikan dari budaya organisasi terhadap kepuasan kerja dosen tetap hal ini terlihat dari tabel koefisien yang menunjukkan nilai signifikansi $=0.029$ dengan $\alpha=5 \%$, maka dapat disimpulkan bahwa $\mathrm{H}_{0}$ ditolak artinya terdapat pengaruh positif yang signifikan Budaya Organisasi dengan kepuasan kerja dengan tingkat keyakinan 95\%. Hal ini juga terlihat dari nilai R Square yang menginformasikan bahwa koefisien determinasi mengindikasikan bahwa 68,54 \% dari kepuasan kerja dapat dijelaskan oleh budaya organisasi sementara sisanya dapat dijelaskan oleh faktor-faktor lainnya. Hal ini berarti sejalan dengan beberapa teori mengenai hal ini pengaruh budaya organisasi terhadap kepuasan kerja yang telah di ungkapkan oleh beberapa pakar.

\section{Saran}

Hasil penelitian ini dapat menunjukkan bahwa budaya organisasi yang diterapkan UBM memiliki pengaruh psotif yang signifikan terhadap kepuasan kerja dosen tetap Universitas Bunda Mulia maka dari hasil tersebut dapat disarankan untuk mempertahankan dan tentunya juga melakukan perbaikan dalam penerapan budaya kerja karena hal ini dapat karena kepuasan kerja dari karyawan dapat memberikan efek yang menunjang pencapaian tujuan perusahaan dalam hal ini Universitas Bunda Mulia

\section{DAFTAR PUSTAKA}

Aritonang R., Lerbin R., 2002. Peramalan Bisnis, Ghalia Indonesia. Jakarta

Iqbal, Muhammad., 2007, Pelayanan yang Memuaskan, PT Elex Media Komputindo, Jakarta 
Robbins, Stephen P., 2006. Perilaku Organisasi: Konsep, Kontroversi, Aplikasi., Jilid 1, Prenhalindo, Jakarta.

Robbins, Stephen P., 2006. Perilaku Organisasi.. Edisi kesepuluh, Indeks, Jakarta

Sedarmayanti, 2001, Sumber Daya Manusia Dan Produktivitas Kerja, Mandar Maju, Bandung

Sinungan, M., 2003, Produktivitas Apa Dan Bagaimana., Bumi Aksara, Jakarta

Singgih Santoso, 2005, Menggunakan SPSS untuk Statistik Parametrik, PT Elexmedia Komputindo, Jakarta

Sugiyono, 2006, Metode Penelitian Bisnis, Edisi kesepuluh, Alfabeta, Bandung.

Wirawan, 2007, Budaya dan Iklim Organisasi: Teori Aplikasi dan Penelitian, Salemba Empat, Jakarta 